\title{
Cardiac dysrhythmias after thoracotomy
}

\author{
P. Ghosh ${ }^{1}$ and B. C. Pakrashi ${ }^{2}$ \\ From The Devon and Exeter Clinical Area
}

A total of Ioo patients undergoing thoracotomy for noncardiac surgery had serial electrocardiograms recorded. Of these, 34 developed cardiac dysrhythmia of which atrial fibrillation was the commonest type. All patients developing dysrhythmia were over 45 years of age and all but two of the episodes of atrial fibrillation and atrial flutter were seen in patients with bronchogenic carcinoma. Most of the dysrhythmias were fleeting in nature and atrial fibrillation almost invariably reverted to sinus rhythm during digitalization. Two cases of atrial flutter were treated by DC shock. None of those with ectopic beats only required any treatment. Possible mechanisms are discussed.

Cardiac dysrhythmias are not infrequent complications of noncardiac thoracic operations (Currens, White, and Churchill, 1943; Bailey and Betts, 1943; Massie and Valle, 1947; Cerney, 1957; Epstein, 1958; Hurt and Bates, 1958). The reported incidence varies from 9 per cent to $2 \mathrm{I}$ per cent and atrial fibrillation is the commonest dysrhythmia. We describe a prospective study undertaken in an attempt to identify possible predisposing or precipitating factors and to assess therapeutic implications.

\section{Material and methods}

A total of 100 consecutive patients who, in 19661967, underwent thoracotomy for noncardiac surgery was included in the study. Details of diagnosis and type of operations are given in Tables 1 and 2. There were 64 male and 36 female patients in this group and their ages varied from I2 to 77 years. Of the 100 patients, 86 were over 45 years of age. Bronchogenic carcinoma (52 patients) and hiatus hernia (24 patients) were the commonest diagnoses. Others included gastrooesophageal carcinoma, bronchiectasis, pulmonary tuberculosis, and sarcoidosis. 40 patients had pneumonectomy or lobectomy, 36 had thoracotomy for lung biopsy or were found to be inoperable, and 24 had transthoracic repair of hiatus hernia. 36 patients had evidence of malignant lymphadenopathy and 8 had lymph node enlargement due to non-malignant disease. Preoperatively, I2-lead electrocardiography with a long strip of lead II or VI was carried out routinely. During operation, the electrocardiogram was dis-

Received 23 June 197r.

1 Present address: Addenbrooke's Hospital, Cambridge, and University of Cambridge.

2 Present address: The General Infirmary, Leeds I. played oscilloscopically and any dysrhythmia recorded. After operation, the pulse was checked hourly for the first 72 hours and then 4 hourly for another 96 hours. The electrocardiogram was recorded each time dysrhythmia was noted. During the first week an electrocardiogram was recorded daily as most dysrhythmia occurs during this period (Massie and Valle, I947; Epstein, 1958). With the onset of atrial fibrillation, an arterial blood sample was taken in a heparinized syringe and the percentage oxygen saturation was measured by Kipp haemoreflector.

\section{Results}

Thirty-four patients developed dysrhythmia in the postoperative period. Atrial fibrillation occurred in 16 patients and 2 patients developed atrial flutter. Atrial or nodal ectopic beats occurred in 8 patients; they were never numerous though short bursts of ectopic beats were noted at times. Ventricular ectopic beats occurred in 12 patients; in 4 cases they were associated with atrial fibrillation and in another 4 with supraventricular ectopic beats.

Of 52 patients operated on for bronchogenic carcinoma, dysrhythmia was seen in 26. Io of 20 patients in whom the pericardium was opened developed dysrhythmia. 16 of 36 patients with lymph node secondaries developed dysrhythmia. Only one patient with non-malignant lymphadenopathy developed atrial fibrillation. This patient was hypertensive but had a normal preoperative electrocardiogram.

Only 2 of 16 patients had arterial oxygen saturation below 94 per cent at the onset of atrial fibrillation, the figures being 93.5 per cent and 89.5 per cent. 
TABLE I Incidence of dysrhythmia according to nature of lesion

\begin{tabular}{|c|c|c|c|c|c|}
\hline \multirow[b]{2}{*}{ Nature of lesion } & \multirow[b]{2}{*}{$\begin{array}{l}\text { No. of } \\
\text { patients }\end{array}$} & \multicolumn{4}{|c|}{ No. developing dysrhythmia } \\
\hline & & $\begin{array}{l}\text { Atrial } \\
\text { fibrillation }\end{array}$ & $\begin{array}{l}\text { Atrial } \\
\text { flutter }\end{array}$ & $\begin{array}{l}\text { Ventricular } \\
\text { ectopics }\end{array}$ & $\begin{array}{l}\text { Supraventricular } \\
\text { ectopics }\end{array}$ \\
\hline Bronchial carcinoma & 52 & 14 & 2 & 8 & 6 \\
\hline Hiatus hernia & 24 & - & - & I & I \\
\hline Gastric carcinoma & I & - & - & - & - \\
\hline Others $\nmid$ & 23 & 2 & - & 3 & $\mathbf{I}$ \\
\hline Total & 100 & 16 & 2 & 12 & 8 \\
\hline
\end{tabular}

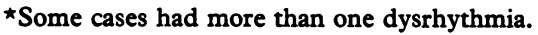

†Includes sarcoidosis, tuberculosis, bronchiectasis, etc.

$$
\text { - }
$$

\section{Discussion}

The incidence of dysrhythmia found in this series $(34 \%)$ is similar to the findings of Hurt and Bates (1958) in patients undergoing thoracotomy without quinidine prophylaxis, - but higher than the reported incidence of 9 to $2 \mathrm{I}$ per cent in other published series (Bailey and Betts, 1943; Currens et al., 1943; Massie and Valle, 1947; Cerney, 1957). Daily routine electrocardiography may have contributed to the higher incidence, especially of supraventricular and ventricular ectopic beats.

- The majority of the dysrhythmias seen were fleeting in nature, as also noted by Massie and Valle (1947) and by Cerney (1957). All patients who developed atrial fibrillation received digoxin with the onset of dysrhythmia and all but one reverted to sinus rhythm, usually within 24-48 hours. The first patient - with atrial flutter, though digitalized, remained in atrial flutter with a ventricular rate of 160 a minute and sinus rhythm was restored with DC shock. The second patient was treated with DC shock immediately.

The dysrhythmia did not seriously affect the circulatory state in any of our patients. There , was no death directly or indirectly attributable to dysrhythmia in this series, and published - :eports show 3 deaths in which dysrhythmia might have been a contributory factor (Cerney, 1957; Epstein, 1958); one of these patients also had pre-existing coronary heart disease.

Age appears to be an important factor in the incidence of dysrhythmia. All the patients developing dysrhythmia in this series were over 45 years and this finding is similar to other published series.

Twenty-four of our patients were either hypertensive or had abnormal electrocardiograms preoperatively and Io of these developed some form of dysrhythmia.

Dysrhythmias appear to be commoner after lobectomy and pneumonectomy compared with thoracotomy for repair of hiatus hernia, lung biopsy for non-malignant lesion, etc. In a collection of 82 patients developing dysrythmia, from published reports (Bailey and Betts, 1943; Currens et al., 1943; Massie and Valle, 1947; Cerney, 1957), and including the present series, 66 of them were operated on for carcinoma of bronchus or oesophagus. The nature of the lesion may thus be contributory as most lobectomies and pneumonectomies were undertaken for a malignant lesion.

Hypoxia has been suggested by Massie and Valle (1947) and Cerney (1957) as a possible factor in the production of dysrhythmia. No

TABLE 2 Dysrhythmia according to type of operation *

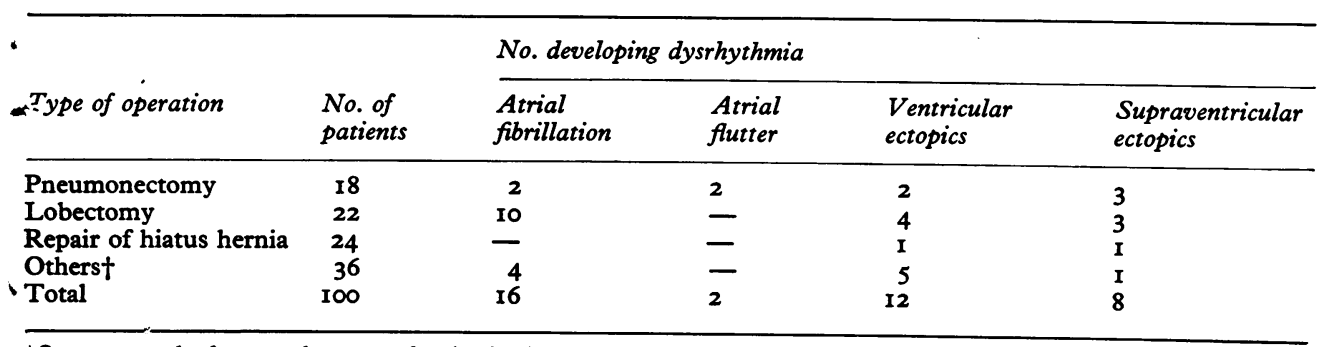

Some cases had more than one dysrhythmia.

tIncludes lung biopsy and exploration only. 
measurement of either the oxygen saturation or oxygen tension in the arterial blood was made in their series. In our study, arterial oxygen saturation was measured in 16 cases with the onset of atrial fibrillation and in only 2 cases was it below 94 per cent. Lack of correlation of generalized hypoxia with dysrhythmia incidence is in accordance with the experimental evidence of Iglauer, Davis, and Altschule (r94I).

Vagal irritation due either to inflammation of the bronchial stump (Bailey and Betts, 1943) or to change of intrathoracic pressure (Currens et al., 1943) has been suggested as a possible precipitating factor. However, the dysrhythmias are commonly transient, usually less than 24 hours in duration, and they occur usually between 2 and 7 days after operation. If operative trauma caused dysrhythmias through vagal irritation (due either to inflammation or change of intrathoracic pressure), it is unlikely they would occur so late or that sinus rhythm would so soon be resumed. Whether postoperative metabolic changes play any role remains conjectural.

The role of general anaesthesia is difficult to ascertain. It is unlikely that it played any part in the pathogenesis of the dysrhythmias in this series, as most of the patients undergoing repair of hiatus hernia needed much longer periods of anaesthesia but had a much lower incidence of dysrhythmia.

Digitalis holds pride of place in the management of these postoperative dysrhythmias and is probably best given at their onset. There is little justification for its general use prophylactically since such use does not significantly alter the incidence of dysrhythmia (Epstein, 1958), and the time involved in gaining control with rapid digitalization (at onset) is rarely critical. Where there is urgency, then DC shock may be preferred, and in such cases there may be greater risk of serious dysrhyth$\mathrm{mia}$ in the presence of digitalis (Kleiger and Lown, 1966; Szekely et al., 1969).

We wish to thank Mr. J. L. Griffith for allowing us to study the patients under his care, Dr. D. W. Evans for help in preparation of this paper, and Mr. F. J. Chadd for technical assistance.

\section{References}

Bailey, C. C., and Betts, R. H. (1943). Cardiac arrhythmias following pneumonectomy. New England fournal of Medicine, 229, 356.

Cerney, C. I. (1957). The prophylaxis of cardiac arrhythmias complicating pulmonary surgery. fournal of Thoracic Surgery, 34, 105.

Currens, J. H., White, P. D., and Churchill, E. D. (1943). Cardiac arrhythmias following thoracic surgery. New England fournal of Medicine, 229, 360.

Epstein, E. J. (1958). Arrhythmias complicating the surgical treatment of lung carcinoma. British fournal of Tuberculosis and Diseases of the Chest, 52, 195.

Hurt, R. L., and Bates, M. (1958). The value of quinidine in the prevention of cardiac arrhythmias after pulmonary resection. Thorax, 13, 39.

Iglauer, A., Davis, D., and Altschule, M. D. (194I). Auricular fibrillation in normal intact animals after the intravenous injection of Mecholyl. American Heart fournal, 22, 47.

Kleiger, R., and Lown, B. (1966). Cardioversion and digitalis. II. clinical studies. Circulation, 33, 878.

Massie, E., and Valle, A. R. (1947). Cardiac arrhythmias complicating total pneumonectomy. Annals of Internal Medicine, 26, 231.

Szekely, P., Wynne, N. A., Pearson, D. T., Baston, G. A., and Sideris, D. A. (1969). Direct current shock and digitalis; a clinical and experimental study. British Heart fournal, 31, 91.

Requests for reprints to Dr. P. Ghosh, Addenbrooke's Hospital, Trumpington Street, Cambridge $\mathrm{CB}_{2} \mathrm{IQE}$. 